\title{
Predictors of Hospitalization in Patients With Transient Ischemic Attack or Minor Ischemic Stroke
}

\author{
Moira K. Kapral, Ruth Hall, Jiming Fang, Peter C. Austin, Frank L. Silver, Leanne \\ K. Casaubon, David J. Gladstone, Melissa Stamplecoski, Jack V. Tu
}

\begin{abstract}
Background: Transient ischemic attack (TIA) and minor stroke are associated with a substantial risk of subsequent stroke; however, there is uncertainty about whether such patients require admission to hospital for their initial management. We used data from a clinical stroke registry to determine the frequency and predictors of hospitalization for TIA or minor stroke across the province of Ontario, Canada. Methods: The Ontario Stroke Registry collects information on a population-based sample of all patients seen in the emergency department with acute stroke or TIA in Ontario. We identified patients with minor ischemic stroke or TIA included in the registry between April 1, 2008, and March 31, 2011, and used multivariable analyses to evaluate predictors of hospitalization. Results: Our study sample included 8540 patients with minor ischemic stroke or TIA, $47.2 \%$ of whom were admitted to hospital, with a range of $37.6 \%$ to $70.3 \%$ across Ontario's 14 local health integration network regions. Key predictors of admission were preadmission disability, vascular risk factors, presentation with weakness, speech disturbance or prolonged/persistent symptoms, arrival by ambulance, and presentation on a weekend or during periods of emergency department overcrowding. Conclusions: More than one-half of patients with minor stroke or TIA were not admitted to the hospital, and there were wide regional variations in admission patterns. Additional work is needed to provide guidance to health care workers around when to admit such patients and to determine whether discharged patients are receiving appropriate follow-up care.
\end{abstract}

RÉSUMÉ: Variables prédictives d'hospitalisation chez des patients victimes d'une ischémie cérébrale transitoire ou d'un AVC mineur. Contexte: Une ischémie cérébrale transitoire (ICT) et un AVC mineur sont associés au risque notable d'être victime d'un autre AVC. Il subsiste cependant des doutes quant à la nécessité d'hospitaliser des patients pour un suivi initial. Nous avons donc utilisé les données d'un registre clinique concernant les AVC pour déterminer la fréquence et les variables prédictives d'une hospitalisation à la suite d'une ICT ou d'un AVC mineur partout en Ontario (Canada). Méthodes: Le Registre de l'AVC de l'Ontario recueille des données au sein d'un échantillon représentatif composé de tous les patients examinés dans un service d'urgence ontarien à la suite d'un ICT ou d'un AVC mineur. Nous avons ainsi identifié les patients victimes d'une ICT et d'un AVC mineur inclus dans le registre entre le 1er avril 2008 et le 31 mars 2011. Nous avons ensuite procédé à des analyses multi-variables afin d'évaluer les variables prédictives d'une hospitalisation. Résultats: L'échantillon visé par notre étude incluait 8540 patients victimes d'une ICT ou d'un AVC mineur ; sur ce total, 47,2 \% ont été hospitalisés, les pourcentages variant de 37,6 \% à 70,3\% dans les 14 Réseaux locaux d'intégration des services de santé (RLISS) de l'Ontario. Les principales variables prédictives d'une hospitalisation se sont révélées être un handicap antérieur à cette hospitalisation, des facteurs de risque vasculaire, des signes de faiblesse, des troubles de la parole ou des symptômes persistants et prolongés de ces troubles, une arrivée en ambulance et une visite à l'hôpital les fins de semaine ou lorsque les services d'urgence sont encombrés. Conclusions: Plus de la moitié des patients victimes d'un AVC mineur ou d'une ICT n'a pas été hospitalisée. Qui plus est, on peut noter de fortes variations régionales en ce qui regarde la tendance à l'hospitalisation. Il est aussi nécessaire de fournir au personnel de la santé des lignes directrices pour savoir s'il est nécessaire ou non d'hospitaliser tels patients et si ceux ayant obtenu leur congé bénéficient d’un suivi adéquat.

Keywords: Health Services Research, hospitalization, registries, stroke, TIA, transient ischemic attack doi:10.1017/cjn.2016.12

Can J Neurol Sci. 2016; 43: 523-528

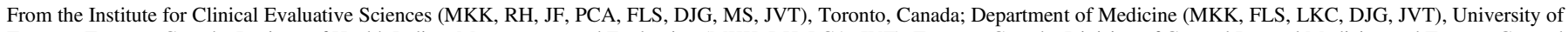

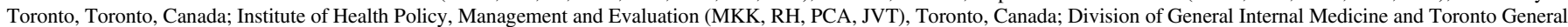
Research Institute (MKK), University Health Network, Toronto, Canada; Sunnybrook Research Institute (MKK, PCA, DJG, JVT), Toronto, Canada; Division of Neurology (FLS),

University Health Network, Toronto, Canada; Division of Neurology (DJG), Division of Cardiology (JVT), Sunnybrook Health Sciences Centre, Toronto, Canada. Received August 31, 2015. Final Revisions Submitted December 31, 2015. Date of Acceptance January 7, 2016.

Correspondence to: Moira K. Kapral, Toronto General Hospital, 14EN 215 - 200 Elizabeth Street, Toronto, Ontario M5G 2C4 Canada Email: moira.kapral@uhn.ca 
Transient ischemic attack (TIA) is associated with a substantial short-term risk of recurrent stroke. ${ }^{1}$ Although observational studies suggest that prompt assessment and risk factor modification can reduce the risk of subsequent stroke, ${ }^{2,3}$ there is ongoing debate about the relative merits and disadvantages of hospitalization versus outpatient care in such patients. ${ }^{4-7}$

Prediction scores have been developed to estimate the risk of recurrent stroke; these generally incorporate clinical factors (age, comorbid conditions) and presenting symptoms (weakness, speech disturbance, duration of symptoms), with some scores also including the results of initial brain or vascular imaging. ${ }^{8-12}$ Although many clinical practice guidelines recommend hospitalization for patients with risk scores above a certain cutoff (typically an age, blood pressure, clinical features, duration of symptoms $[\mathrm{ABCD}]^{2}$ score $>2$ or 3 ), such risk scores may perform less well than the initial validation studies suggested, ${ }^{13,14}$ contributing to further uncertainty about when to hospitalize patients with minor stroke or TIA.

We used data from a clinical stroke registry in Ontario, Canada, linked with administrative databases, to determine the association between patient and system-level factors with the proportion of patients with TIA or minor stroke admitted to hospital. We hypothesized that both patient-level factors (such as presenting symptoms and comorbid conditions) and system-level factors (such as availability of a stroke prevention clinic) would be associated with hospitalization.

\section{METHODS}

\section{Data Sources and Study Sample}

The Ontario Stroke Registry (formerly known as the Registry of the Canadian Stroke Network) performs a biennial audit on a population-based random sample of patients seen at all acute care institutions in Ontario. ${ }^{15}$ Events are reviewed by trained neurology research personnel and only included in the registry database if chart review confirms a diagnosis of stroke or TIA. The registry database includes information on stroke type and severity, presenting symptoms and comorbid conditions, and validation by duplicate chart abstraction has shown almost perfect agreement (kappa scores of $>0.80$ ) for key variables including age, sex, stroke type, admission to hospital, and the diagnoses of diabetes and hypertension $^{15}$ and substantial agreement (kappa scores of 0.61-0.80) for presenting symptoms (unpublished data). For the present study, we included all patients with TIA (defined as transient focal neurological symptoms of less than 24 hours' duration, with no evidence of infarction on neuroimaging) or minor ischemic stroke (defined as a Canadian Neurological Scale score of greater than 10, corresponding to a National Institutes of Health Stroke Scale score of $<3$ ) who were aged 18 years or older and who were seen in the emergency department (ED) or admitted to hospital between April 1, 2008, and March 31, 2009, or April 1, 2010, and March 31, 2011. For patients with more than one ED presentation during the study period, only the first event was included.

The Ontario Stroke Registry is housed at the Institute for Clinical Evaluative Sciences (ICES) where it is linked to population-based administrative databases using unique encoded patient identifiers. We used the National Ambulatory Care Reporting System database to identify times of ED overcrowding, defined as a mean length of stay in the ED of greater than 4 hours for patients of similar acuity seen in the ED on the same shift as the index patient, ${ }^{16}$ the 2010 Canada Census to provide information on socioeconomic status based on median neighbourhood income for each patient and the 2010 Stroke Secondary Prevention Clinic Resource Survey to provide information on the characteristics of stroke prevention clinics.

\section{Analysis}

We determined the proportion of patients admitted to hospital in the overall cohort, in the subgroups with TIA alone and minor ischemic stroke alone, and by region, based on Ontario's 14 Local Health Integration Network regions. We compared baseline characteristics between admitted and discharged patients using chi-square tests for categorical variables and the Wilcoxon rank-sum test for continuous variables.

We used multiple logistic regression to evaluate the effect of the following predictor variables on the odds of hospital admission: (1) patient characteristics (age, sex, place of residence before admission, rural residence, neighbourhood income group, prestroke functional status, and comorbid conditions [defined by having documentation of any of these in the patient chart] including diabetes mellitus, hypertension, smoking, atrial fibrillation, and coronary artery disease); (2) characteristics of the index event (motor or speech deficits, duration of symptoms, systolic blood pressure $>140 \mathrm{~mm} \mathrm{Hg}$ on presentation, diastolic blood pressure $>90 \mathrm{~mm} \mathrm{Hg}$ on presentation, $\mathrm{ABCD}^{2}$ score $^{7}$ ); (3) characteristics of the care encounter (ED overcrowding, presentation off-hours); and (4) hospital characteristics (hospital size, designation as a stroke centre, availability of a stroke unit, presence of a stroke prevention clinic on-site, and number of days of operation of the stroke prevention clinic) and health region of care. We used a hierarchical logistic regression that incorporated hospital-specific and region-specific random effects to account for the clustering of patients within hospitals and regions. We used variance partition coefficients to describe the percentage of variation in the odds of admission that could be attributed to the patient level versus institutional and regional levels.

\section{Ethics}

Chart review for the Ontario Stroke Registry (OSR) is done without patient consent because ICES is named as a prescribed entity under provincial privacy legislation. This study was approved by the Sunnybrook Health Sciences Centre Research Ethics Board.

\section{RESULTS}

The study sample consisted of 8540 patients seen in the ED with TIA or minor ischemic stroke between April 1, 2008, and March 31, 2011. Overall, 4030 (47.2\%) were admitted to hospital. Baseline characteristics of participants are shown in Table 1.

In the multivariable analyses, significant predictors of hospital admission were disability before admission (adjusted odds ratio [AOR], 2.20; 95\% confidence interval [CI], 1.75-2.76), diabetes (AOR, 1.14; 95\% CI, 1.00-1.29), hypertension (AOR, 1.15; 95\% CI, 1.02-1.31), smoking (AOR, 1.05; 95\% CI, 1.05-1.46), atrial fibrillation (AOR, 1.71; 95\% CI, 1.47-1.99), presentation with weakness (AOR, 1.17; 95\% CI, 1.05-1.31), speech disturbance (AOR, 1.38; 95\% CI, 1.22-1.56) or prolonged/persistent symptoms (AOR, 3.05; 95\% CI, 2.18 2.76), arrival by ambulance (AOR, 2.45; 
Table 1: Baseline characteristics of patients with minor ischemic stroke/TIA admitted to hospital or discharged from the ED

\begin{tabular}{|c|c|c|c|}
\hline & \multicolumn{3}{|c|}{$\mathrm{N}(\%)$} \\
\hline & $\underset{4510}{\text { Discharged } N}=$ & $\begin{array}{c}\text { Admitted } N= \\
4030\end{array}$ & p Value \\
\hline Index event & & & $<0.001$ \\
\hline TIA & $3824(85)$ & $1683(42)$ & \\
\hline Stroke & $686(15)$ & $2347(58)$ & \\
\hline Female & $2189(48)$ & $1925(48)$ & 0.48 \\
\hline Median age, years (IQR) & $73(63-82)$ & $75(64-83)$ & $<0.001$ \\
\hline Rural residence & $778(17)$ & $671(17)$ & 0.46 \\
\hline Income quintile* & & & $<0.001$ \\
\hline 1 (lowest) & $849(19)$ & $872(22)$ & \\
\hline 2 & $936(21)$ & $798(20)$ & \\
\hline 3 & $887(20)$ & $789(20)$ & \\
\hline 4 & $981(22)$ & $749(19)$ & \\
\hline 5 (highest) & $827(18)$ & $798(20)$ & \\
\hline Long-term care residence & $37(1)$ & $32(1)$ & 0.89 \\
\hline Disabled before event (mRS 35) & $228(5)$ & $424(10)$ & $<0.001$ \\
\hline Diabetes & $1022(23)$ & $1108(28)$ & $<0.001$ \\
\hline Hypertension & $2820(52)$ & $2849(71)$ & $<0.001$ \\
\hline Hyperlipidemia & $1770(39)$ & $1775(44)$ & $<0.001$ \\
\hline Current smoker & $567(13)$ & $663(16)$ & $<0.001$ \\
\hline Dementia & $261(6)$ & $248(6)$ & 0.47 \\
\hline Atrial fibrillation & $488(11)$ & 677 (17) & $<0.001$ \\
\hline Coronary artery disease & $988(22)$ & $1046(26)$ & $<0.001$ \\
\hline Prior stroke/TIA & $1129(25)$ & $976(24)$ & 0.38 \\
\hline $\mathrm{SBP} \geq 190$ & $398(9)$ & $453(11)$ & $<0.001$ \\
\hline $\mathrm{DBP} \geq 90$ & $1070(24)$ & $1146(28)$ & $<0.001$ \\
\hline Weakness & $2182(48)$ & $2316(58)$ & $<0.001$ \\
\hline Speech disturbance & $1608(36)$ & $1650(41)$ & $<0.001$ \\
\hline Symptoms persisting $\geq 60$ minutes & $2019(45)$ & $3220(80)$ & $<0.001$ \\
\hline $\mathrm{ABCD}^{2}$ score $\geq 2$ & $4133(92)$ & $3927(97)$ & $<0.001$ \\
\hline Transported by ambulance & $1651(37)$ & $2239(56)$ & $<0.001$ \\
\hline $\begin{array}{l}\text { Presentation on overcrowded ED } \\
\text { shift* }\end{array}$ & $3270(72)$ & $3040(75)$ & 0.002 \\
\hline $\begin{array}{l}\text { Time from symptom onset to ED } \\
\text { arrival }\end{array}$ & & & $<0.001$ \\
\hline$<6$ hours & $2679(59)$ & $2085(52)$ & \\
\hline 6-24 hours & $1094(24)$ & $1102(27)$ & \\
\hline$>24$ hours & $737(16)$ & $843(21)$ & \\
\hline Presentation midnight to 0800 hours & $326(7)$ & $366(9)$ & 0.001 \\
\hline Weekend presentation & $1149(26)$ & $1148(28)$ & 0.002 \\
\hline Hospital designation & & & $<0.001$ \\
\hline Regional stroke centre & $1218(27)$ & $1330(33)$ & \\
\hline District stroke centre & $1395(31)$ & $1304(32)$ & \\
\hline Nondesignated centre & $1897(42)$ & $1396(35)$ & \\
\hline
\end{tabular}

IQR, interquartile range; DBP, diastolic blood pressure; ED, emergency department; mRS, modified Rankin score; SBP, systolic blood pressure; TIA, transient ischemic attack.

*Neighbourhoods were divided into quintiles based on median income from 2006 Canada Census data, in which quintile 1 represents the lowest and quintile 5 represents the highest income quintile. An overcrowded ED shift was defined as one in which the mean ED length of stay was greater than 4 hours for patients of similar acuity seen in the same ED shift as the index patient. 
$\underline{\text { Sex }}$

Male vs. Female

Rural Residence

Yes vs. No

Income Quintile

Highest (5) vs. Lowest (1)

Index Event

TIA vs. Ischemic Stroke

Disabled Prior to Event

Yes vs. No

Hypertension

Yes vs. No

Hyperlipidemia

Yes vs. No

Current Smoker

Yes vs. No

Atrial Fibrillation

Yes vs. No

Weakness at Presentation

Yes vs. No

Speech Disturbance at Presentation

Yes vs. No

Duration of Symptoms

$<10$ minutes vs. $10-59$ minutes

$\geq 60$ minutes vs. $10-59$ minutes

Transported by Ambulance

Yes vs. No

Emergency Department Overcrowding

Yes vs. No

Weekend Presentation

Yes vs. No

Hospital Designation

Designated Stroke Center vs.

Non-Designated Stroke Center
Odds Ratio (95\% Cl)

$0.98(0.87-1.09)$

$1.10(0.92-1.32)$

$1.13(0.95-1.35)$

$0.15(0.13 \cdot 0.17)$

$2.20(1.75 \cdot 2.76)$

$1.15(1.02-1.31)$

$1.24(1.10-1.40)$

$1.24(1.05-1.46)$

$1.71(1.47-1.99)$

$1.17(1.05-1.31)$

$1.38(1.22-1.56)$

$0.86(0.67-1.10)$

$3.05(2.63-3.54)$

$2.45(2.18-2.76)$

$1.26(1.06-1.5)$

$1.14(1.01-1.29)$

$1.16(0.73-1.87)$

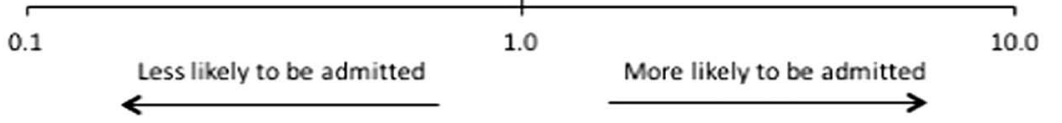

Figure 1: Forest plot of predictors of admission in patients with TIA and minor stroke.

95\% CI, 2.18-2.76), and presentation on a weekend (AOR, 1.14; 05\% CI, 1.01-1.29) or during period of ED overcrowding (AOR, 1.26; 95\% CI, 1.06-1.50) (Figure 1). Presentation with TIA rather than minor stroke was associated with a reduced odds of admission (AOR, 0.15; 95\% CI, 0.13-0.17). Age, sex, neighbourhood income, rural residence, time from symptom onset to hospital arrival, hospital designation (regional or district stroke centre), and teaching status were not significant predictors of 
admission, nor was the presence of a stroke unit or a stroke prevention clinic on-site (Figure 1). Results were similar when the subgroups with minor stroke and TIA were analyzed separately (data not shown).

There were variations in the proportion of patients admitted across regions, from a low of $37.5 \%$ to a high of $70.3 \%$. After adjusting for patient, hospital, and regional characteristics, $88.4 \%$ of the remaining variation was due to between-patient variation, $11 \%$ was due to between-hospital variation, and $0.6 \%$ was due to between-region variation.

\section{Discussion}

In this contemporary population-based study, more than one-half of patients seen in the ED across the province of Ontario with TIA or minor ischemic stroke were not admitted to hospital, and there were wide regional variations in the proportion of patients admitted.

We found that the key predictors of hospital admission were preadmission dependence and vascular risk factors as well as high-risk presenting features such as weakness, speech disturbance, or prolonged/persistent symptoms. This likely reflects clinical decision-making based on the need to manage comorbid conditions as well as the use of prognostic scores such as the $\mathrm{ABCD}^{2}$ score to determine whether patients should be admitted or discharged. ${ }^{8,9}$ However, the uneven performance of such scoring systems suggests a need for updated strategies to guide decisions about admission of patients with minor stroke and TIA. More recent risk prediction scores that incorporate the findings of initial imaging and other investigations may improve patient risk stratification. ${ }^{14}$

Studies from the United States have also documented admission rates for TIA in the range of $54 \%$ to $91 \%$, with regional variations, ${ }^{17-19}$ although one study of patients seen in the era before publication of risk prediction tools found that only $14 \%$ of patients with TIA were admitted, and that admission only weakly correlated with the $\mathrm{ABCD}^{2}$ score. $^{20}$ Another study using data from the National Emergency Department Sample evaluated predictors of hospitalization and found that, after adjustment for age and comorbid conditions, higher median household income, Medicare insurance type, and care at a teaching hospital were all associated with admission; the administrative data sources used for this study did not have information on presenting symptoms, so the effect of these and other clinical factors on the likelihood of admission could not be evaluated. ${ }^{19}$ In contrast, we found that hospital factors such as annual stroke patient volumes, designation as a stroke centre, rural location, teaching status, and having a stroke unit or a stroke prevention clinic on site were not associated with hospitalization, nor was median neighbourhood income. These differences may be a reflection of care provided within Canada's universal health care system.

Our finding of a greater likelihood of hospitalization among patients presenting off hours or on weekends likely reflects a limited ability to coordinate and obtain rapid outpatient care at such times. Although individual patient circumstances will dictate admission in many cases, particularly those in which inpatient rehabilitation or management of comorbid conditions is required or in which there are concerns about the patient's ability to return for follow-up, timely outpatient care is an alternative to hospitalization for many other patients. There is increasing recognition that it is the timing of the tests and treatments that is most important, rather than the specific setting in which these are provided. Rapid outpatient TIA assessment units have been successfully implemented in some jurisdictions internationally, but were not widely available in Ontario at the time of our study. ${ }^{21-25}$

Our study had some limitations. It was not designed to determine which factors were associated with outcomes after stroke, to develop a risk prediction score, or to evaluate potential differences in outcomes between patients who were admitted to hospital and discharged from the ED. Although the Ontario Stroke Registry included detailed information on sociodemographic factors and presenting symptoms, there may have been specific features of the index event that prompted hospitalization but were not available in our data sources, such as lack of social supports, need for management of comorbid illnesses, availability of vascular neurologists, and patient preferences. In addition, we did not have information on whether hospitals used institutional protocols or local criteria for admission, or whether a local rapid TIA clinic was available, all factors that could have affected admission rates. Although charts were reviewed by trained neurology research nurses who consulted with stroke specialists and patients in which the diagnosis was uncertain were excluded from the analysis, there may have been differential misclassification of ED patients in whom TIA/stroke mimics are more common than in admitted patients, and we do not have information on how many discharged patients were ultimately diagnosed with something other than stroke/TIA. Finally, Ontario has a well-established regional system of stroke care that operates within a universal health care system, and some of our findings, such as the lack of association between income and hospitalization, may not be generalizable to other settings. However, our study strengths include the use of data from a large, population-based provincial registry with detailed information on presenting characteristics.

In summary, we found that almost one-half of patients seen in the ED with TIA and minor stroke were admitted to hospital. Although clinical factors such as comorbid conditions and presenting symptoms were the strongest predictors of admission, system factors such as presentation off-hours and on weekends were also associated with hospitalization, suggesting that some admissions could be avoided through improved access to outpatient care. Future activities should focus on updating clinical practice recommendations to provide more guidance on which patients with TIA/minor stroke warrant admission, and on developing and implementing appropriate alternatives to inpatient care.

\section{ACKNOWLEDGEMENTS}

We thank Brennan Rashkovan for his assistance with manuscript preparation.

The Ontario Stroke Registry is funded by the Canadian Stroke Network and the Ontario Ministry of Health and Long-Term Care (MOHLTC). The Institute for Clinical Evaluative Sciences (ICES) is supported by an operating grant from the MOHLTC. The sponsors had no role in the design and conduct of the study; in the collection, analysis, and interpretation of the data; or in the preparation, review, or approval of the manuscript. The opinions, results, and conclusions reported in this paper are those of the authors and are independent from the funding sources. No endorsement by ICES or the Ontario MOHLTC is intended or should be inferred. 


\section{Disclosures}

MKK is supported by a Career Investigator award from the Heart and Stroke Foundation, Ontario Provincial Office. PCA was previously supported by a Career Investigator award from the Heart and Stroke Foundation, was a consultant for Boehringer Ingelhelm, Inc.'s for RESPECT-ESUS clinical trial, received consulting fees from, honoraria from, and was an advisory board member for Boehringer Ingelhelm, Inc. LKC served as an independent contractor (patient assessor for SURTAVI) for Medtronic and received consulting fees from and was a site principal investigator for NoNO Inc. FLS has served as a speaker for Boehringer Ingelheim Canada and Servier Canada and as a Canadian study coordinator for Boehringer Ingelheim Canada. DJG served on an advisory board for and received speaker's fees from Bayer, BMS, and Pfizer and received speaker's fees from Boehringer Ingelhelm, Inc. JT is supported by a Canada Research Chair in Health Services Research and an Eaton Scholar Award.

\section{REFERENCES}

1. Giles MF, Rothwell PM. Risk of stroke early after transient ischaemic attack: a systematic review and meta-analysis. Lancet Neurol. 2007;6:1063-72.

2. Rothwell PM, Giles MF, Chandratheva A, et al. Effect of urgent treatment of transient ischaemic attack and minor stroke on early recurrent stroke (EXPRESS study): a prospective populationbased sequential comparison. Lancet. 2007;370:1432-42.

3. Lavallée PC, Meseguer E, Abboud H, et al. A transient ischaemic attack clinic with round-the-clock access (SOS-TIA): feasibility and effects. Lancet Neurol. 2007;6:953-60.

4. Amarenco P. Not all patients should be admitted to the hospital for observation after a transient ischemic attack. Stroke. 2012;43:1448-9.

5. Cucchiara BL, Kasner SE. All patients should be admitted to the hospital after a transient ischemic attack. Stroke. 2012;43:1446-7.

6. Donnan GA, Davis SM, Hill MD, Gladstone DJ. Patients with transient ischemic attack or minor stroke should be admitted to hospital. Stroke. 2006;37:1137-8.

7. Lindley RI. Patients with transient ischemic attack do not need to be admitted to hospital for urgent evaluation and treatment. Stroke. 2006;37:1139-40.

8. Rothwell PM, Giles MF, Flossmann E, et al. A simple score (ABCD) to identify individuals at high early risk of stroke after transient ischaemic attack. Lancet. 2005;366:29-36.

9. Johnston SC, Rothwell PM, Nguyen-Huynh MN, et al. Validation and refinement of scores to predict very early stroke risk after transient ischaemic attack. Lancet. 2007;369:283-92.

10. Kiyohara T, Kamouchi M, Kumai Y, et al. ABCD3 and ABCD3-I scores are superior to $\mathrm{ABCD} 2$ score in the prediction of short- and long-term risks of stroke after transient ischemic attack. Stroke. 2014;45:418-25.

11. Merwick Á, Albers GW, Amarenco P, et al. Addition of brain and carotid imaging to the $\mathrm{ABCD} 2$ score to identify patients at early risk of stroke after transient ischaemic attack: a multicentre observational study. Lancet Neurol. 2010;9:1060-9.

12. Coutts SB, Modi J, Patel SK, Demchuk AM, et al. CT/CT angiography and MRI findings predict recurrent stroke after transient ischemic attack and minor stroke: results of the prospective CATCH study. Stroke. 2012;43:1013-7.

13. Perry JJ, Sharma M, Sivilotti MLA, et al. Prospective validation of the $\mathrm{ABCD} 2$ score for patients in the emergency department with transient ischemic attack. CMAJ. 2011;183:1137-45.

14. Hill MD, Coutts SB. Preventing stroke after transient ischemic attack. CMAJ. 2011;183:1127-8.

15. Kapral MK, Silver FL, Richards JA, et al. Registry of the Canadian Stroke Network. Progress Report 2001-2005. Toronto: Institute for Clinical Evaluative Sciences; 2005.

16. Asplin BR. Measuring crowding: time for a paradigm shift. Acad Emerg Med. 2006;13:459-61.

17. Edlow JA, Kim S, Pelletier AJ, Camargo CA Jr. National study on emergency department visits for transient ischemic attack, 1992-2001. Acad Emerg Med. 2006;13:666-72.

18. Durrani-Tariq S, Eskin B, Allegra JR. Admission rates of ED patients with transient ischemic attack have increased since 2000. Am J Emerg Med. 2013;31:1349-51.

19. Chaudhry SA, Tariq N, Majidi S, et al. Rates and factors associated with admission in patients presenting to the ED with TIA in the United States - 2006 to 2008. Am J Emerg Med. 2013; 31:516-9.

20. Josephson SA, Sidney S, Pham TN, Bernstein AL, Johnston SC. Factors associated with the decision to hospitalize patients after transient ischemic attack before publication of prediction rules. Stroke. 2008;39:411-3.

21. Torres MacHo J, Peña Lillo G, Pérez Martínez D, et al. Outcomes of atherothrombotic transient ischemic attack and minor stroke in an emergency department: results of an outpatient management program. Ann Emerg Med. 2011;57:510-6.

22. Olivot JM, Wolford C, Castle J, et al. Two aces: transient ischemic attack work-up as outpatient assessment of clinical evaluation and safety. Stroke. 2011;42:1839-43.

23. Hörer S, Haberl RL, Schulte-Altedorneburg G. Management of patients with transient ischemic attack is safe in an outpatient clinic based on rapid diagnosis and risk stratification. Cerebrovasc. Dis. 2011;32:504-10.

24. Wasserman J, Perry J, Dowlatshahi D, et al. Stratified, urgent care for transient ischemic attack results in low stroke rates. Stroke. 2010;41:2601-5.

25. Wu CM, Manns BJ, Hill MD, Ghali W, et al. Rapid evaluation after high-risk TIA is associated with lower stroke risk. Can J Neurol Sci. 2009;36:450-5. 